\title{
Mucinous cystadenocarcinoma of the appendix in which contrast-enhanced ultrasonography was useful for assessing blood flow in a focal nodular lesion in the tumor cavity: A case report
}

\author{
NORITAKA WAKUI $^{1}$, MITSURU FUJITA ${ }^{1}$, YOSHIYA YAMAUCHI ${ }^{1}$, YUKI TAKEDA $^{1}$, \\ NOBUO UEKI ${ }^{1}$, TAKAFUMI OTSUKA ${ }^{1}$, NOBUYUKI OBA ${ }^{1}$, SHUTA NISHINAKAGAWA ${ }^{1}$, \\ TOSHIKO TAKEZOE ${ }^{2}$, JUNKO HIROYOSHI ${ }^{2}$, YOSHIHARU KONO ${ }^{2}$, SEIICHIRO KATAHIRA ${ }^{2}$, \\ MASAMI MINAGAWA ${ }^{2}$, YASUSHI TAKEDA ${ }^{2}$, SAORI SHIONO ${ }^{3}$ and TATSUYA KOJIMA ${ }^{1}$ \\ Departments of ${ }^{1}$ Internal Gastroenterology and Hepatology, ${ }^{2}$ Surgery and ${ }^{3}$ Pathology, \\ Tokyo Rosai Hospital, Tokyo 143-0013, Japan
}

Received February 1, 2013; Accepted April 25, 2013

DOI: $10.3892 /$ etm.2013.1094

\begin{abstract}
A 63-year-old woman was admitted to hospital with pain in the right lower quadrant. Abdominal computed tomography $(\mathrm{CT})$ revealed a 60 -mm cystic mass at a site corresponding to the appendix. The mass wall on the appendicular ostium was thickened and enhanced by contrast, while calcification was observed in the mass wall on the appendicular tip. No projection was observed in the mass cavity. On abdominal ultrasonography (US), the mass wall on the appendicular ostium was thickened and projections were observed at two sites in the mass cavity. On contrast-enhanced US (CEUS), only one of these projections was enhanced. Based on the thickened and contrast-enhanced wall of the mass on the appendicular ostium on CT and US, as well as the contrast enhancement of a projection on US, the mass was diagnosed as mucinous cystadenocarcinoma of the appendix. Ileocecal resection was subsequently performed on day 10 . A detailed examination of the surgical specimen revealed carcinoma cells in the mass wall on the appendicular ostium. The contrast-enhanced projection was identified as granulation tissue that had grown to come into contact with the tumor, while the non-contrastenhanced projection was identified as solidified mucus. US enabled successful visualization of projections in the mass cavity that were not visible on abdominal CT. CEUS also proved useful for assessing blood flow in these projections.
\end{abstract}

Correspondence to: Dr Noritaka Wakui, Department of Internal Gastroenterology, Tokyo Rosai Hospital, 4-13-21 Omori-Minami, Ota-ku, Tokyo 143-0013, Japan

E-mail: noriwakui@yahoo.co.jp

\section{Abbreviations: CT, computed tomography; US, ultrasonography}

Key words: appendix, mucocele, mucinous cystadenocarcinoma, ultrasound, contrast-enhanced ultrasonography, sonazoid

\section{Introduction}

Mucocele of the appendix is a cystoid extension of the appendix resulting from mucus accumulation in the appendix cavity (1). It is also a rare pathology of the appendix without characteristic clinical symptoms $(2,3)$. Although mucocele of the appendix is often discovered following surgery due to the difficulty in obtaining a preoperative diagnosis, recent advances in imaging technology have led to an improved preoperative diagnostic rate. Kim et al (4) performed a detailed examination of mucocele of the appendix in 17 patients by computed tomography (CT) and ultrasonography (US) and suggested that the presence of a focal nodular lesion in the tumor cavity is an important predictor of malignancy.

The current report describes a case of mucinous cystadenocarcinoma of the appendix in which contrast-enhanced US (CEUS) was useful for the detailed assessment of blood flow in projections in the mass cavity. The radiographic change was observed after 1 year and 7 months. Written informed consent was obtained from the patient.

\section{Case report}

A 63-year-old female was admitted to Tokyo Rosai Hospital with discomfort in the right lower quadrant, which the patient had being experiencing since approximately January 2011. Physical examination revealed no tenderness; however, a palpable, fist-sized mass in the right lower quadrant prompted abdominal CT, which revealed a 60-mm cystic mass at the site corresponding to the appendix with calcification in its wall on the appendicular tip. With no thickening or contrast enhancement in the entire wall of the mass, cystadenoma, as opposed to carcinoma was suspected (Fig. 1). Since the possibility of carcinoma could not be ruled out, surgical removal of the mass was recommended; however, the patient refused surgery and was placed on a careful outpatient follow-up program.

Three months later, the patient returned to the hospital. Abdominal CT revealed no changes compared with the previous examination. The patient was advised to return to 
the outpatient clinic in 3 months; however, the patient did not return. Later, the patient presented with persistent pain in the right lower quadrant, which the patient had experienced since August 2012. On examination, a mass was felt in the right lower quadrant that resembled the one felt previously and tenderness was experienced at the same site. The patient was then admitted for workup. The patient had no history of alcohol or smoking and the prior medical history included surgery for internal hemorrhoids at the age of 59 years. No signifant family history was reported and no oral medication was being used. On admission, the patient had clear sensorium and a blood pressure of $123 / 73 \mathrm{mmHg}$, a pulse rate of 60 beats/min (non-arrhythmic) and a body temperature of $37.5^{\circ} \mathrm{C}$. The palpebral conjunctiva was not anemic and no yellow discoloration of the bulbar conjunctiva was observed. Heart and breath sounds were noted to be clear. The abdomen was flat and soft with a palpable fist-sized mass present in the right lower quadrant. The mass was slightly hard and minimally movable with tenderness; however, no rebound tenderness or muscular rigidity was apparent. The liver and spleen were impalpable. Hematological examination on admission revealed mild anemia (hemoglobin, $11.4 \mathrm{~g} / \mathrm{dl}$ ) and increased inflammatory reaction (C-reactive protein, $6.5 \mathrm{mg} / \mathrm{dl}$ ). No increase in the levels of tumor markers was observed (Table I).

Abdominal CT on day 2 revealed no change in the size of the existing cystic mass from the previous CT scan performed in January 2011; however, it revealed thickening of the mass wall on the appendicular ostium and contrast enhancement at the corresponding site. No projection was observed in the mass cavity (Fig. 2). On abdominal US on day 2, the mass was anechoic overall and demonstrated a partly layered echo pattern. The mass wall on the appendicular ostium was thickened with a $13-\mathrm{mm}$ projection protruding toward the cavity from part of the wall. Another 9-mm projection was also observed in the appendicular tip (Fig. 3).

CEUS was then performed to assess blood flow using a Toshiba SSA-790A US system (Aplio XG; Toshiba Medical Systems, Otawara, Japan) with a $3.75-\mathrm{MHz}$ convex probe (PVT-375BT). Imaging was performed with a mechanical index of 0.21 and the focus was adjusted to the depth of the mass. After imaging conditions were set, Sonazoid (perfluorobutane; GE Healthcare, Oslo, Norway) was infused at the recommended dose of $0.015 \mathrm{ml} / \mathrm{kg}$ via the cubital vein. Contrast enhancement was observed in the thickened wall of the mass on the appendicular ostium and in the projection on the same side; however, not in the projection on the appendicular tip (Fig. 4).

Based on the thickened and contrast-enhanced wall of the mass on the appendicular ostium on abdominal CT and US, as well as contrast enhancement of the projection on the appendicular ostium on US, the mass was diagnosed as mucinous cystadenocarcinoma of the appendix and ileocecal resection was performed on day 10 . The mass was excised with surrounding connective tissue with care taken not to break the mass.

Gross pathological findings. The appendix was swollen with a 60-mm cyst with a glossy white surface. No rupture of the mass was observed (Fig. 5).
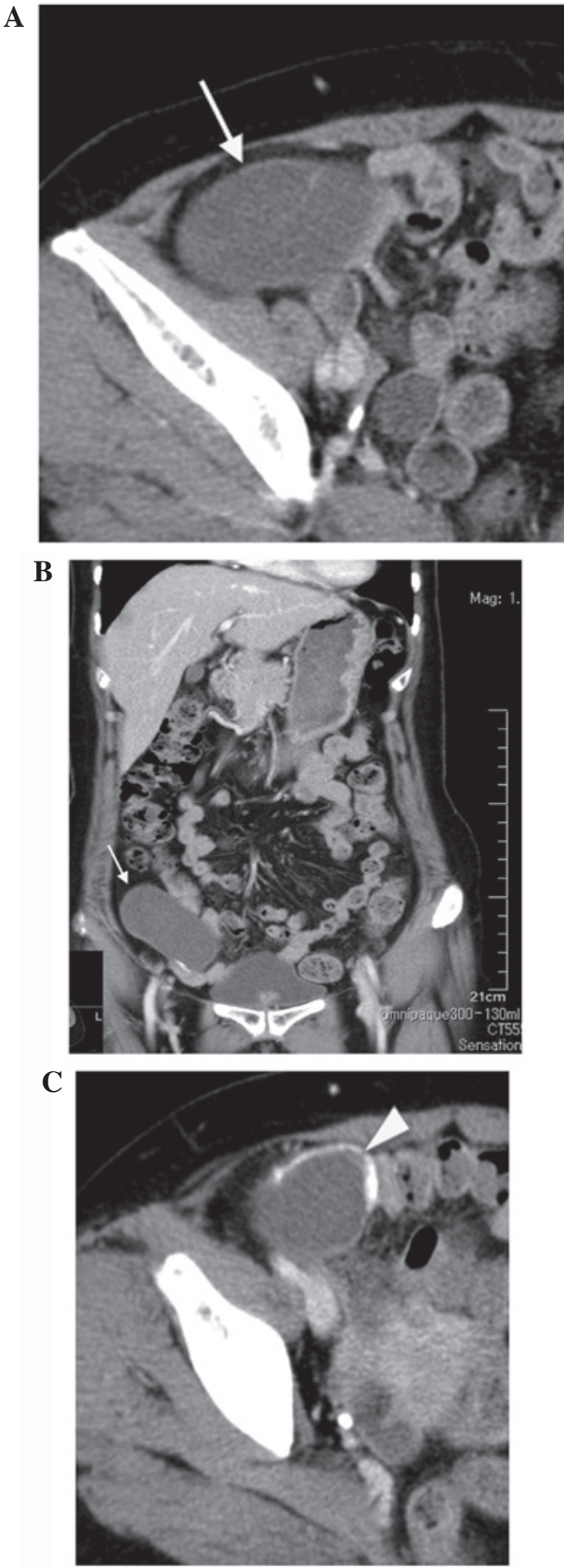

Figure 1. Abdominal computed tomography (CT) scans obtained in January 2011. Axial view (A) and coronal view (B) showing a 60-mm cystic mass at the site corresponding to the appendix, with no thickening or contrast enhancement in its wall. No projection was visible in the mass cavity (arrow). Another axial view (C) demonstrated calcification of the mass wall on the appendicular tip (arrowhead).

Histopathological findings. The mass wall was thickened on the appendicular ostium and accompanied by enlarged nuclei and pseudostratified cells, leading to the diagnosis of adenocarcinoma. The protrusion on the appendicular ostium was located inside the thickened wall and composed of granulation tissue with proliferating capillaries. The protrusion on the appendicular tip was composed of mucus, and part of the wall was calcified (Fig. 6). 
Table I. Blood laboratory findings on admission.

\begin{tabular}{|c|c|}
\hline Diagnostic blood tests & Results \\
\hline \multicolumn{2}{|l|}{ Biochemistry } \\
\hline $\mathrm{CRP}(\mathrm{mg} / \mathrm{dl})$ & 6.5 \\
\hline $\mathrm{Na}(\mathrm{mEq} / \mathrm{l})$ & 137 \\
\hline $\mathrm{K}(\mathrm{mEq} / \mathrm{l})$ & 4.0 \\
\hline $\mathrm{Cl}(\mathrm{mEq} / \mathrm{l})$ & 100 \\
\hline $\mathrm{TP}(\mathrm{g} / \mathrm{dl})$ & 7.9 \\
\hline Alb (g/dl) & 4.0 \\
\hline T Bil (mg/dl) & 0.6 \\
\hline D Bil (mg/dl) & 0.4 \\
\hline AST (IU/1) & 28 \\
\hline ALT (IU/l) & 29 \\
\hline LDH (IU/1) & 151 \\
\hline ALP (IU/l) & 267 \\
\hline GGT (IU/l) & 62 \\
\hline T Cho (mg/dl) & 178 \\
\hline $\mathrm{TG}(\mathrm{mg} / \mathrm{dl})$ & 166 \\
\hline CK (IU/1) & 57 \\
\hline BUN (mg/dl) & 13 \\
\hline $\mathrm{Cr}(\mathrm{mg} / \mathrm{dl})$ & 0.53 \\
\hline $\mathrm{BS}(\mathrm{mg} / \mathrm{dl})$ & 107 \\
\hline HbA1c $(\%)$ & 6.0 \\
\hline $\mathrm{PT}(\%)$ & 86 \\
\hline APTT (sec) & 30.4 \\
\hline \multicolumn{2}{|l|}{ Hematology } \\
\hline WBC (cells/ $\mu 1)$ & 5500 \\
\hline $\mathrm{RBC}($ cells $/ \mu \mathrm{l})$ & $365 \times 10^{4}$ \\
\hline $\operatorname{Hgb}(\mathrm{g} / \mathrm{dl})$ & 11.4 \\
\hline Hct $(\%)$ & 33.2 \\
\hline $\operatorname{PLT}(\mathrm{n} / \mu \mathrm{l})$ & $23.0 \times 10^{4}$ \\
\hline \multicolumn{2}{|l|}{ Tumor marker } \\
\hline CEA (ng/ml) & 2.7 \\
\hline CA19-9 (U/ml) & 3.0 \\
\hline CA125 (U/ml) & 13.1 \\
\hline
\end{tabular}

CRP, C-reactive protein; $\mathrm{Na}$, sodium; $\mathrm{K}$, potassium; $\mathrm{Cl}$, chlorine; $\mathrm{TP}$, total protein; Alb, albumin; T Bil, total bilirubin; D Bil, direct bilirubin; AST, aspartate aminotransferase; ALT, alanine aminotransferase; LDH, lactate dehydrogenase; ALP, alanine phosphatase; GGT, $\gamma$-glutamyl transpeptidase; T Cho, total cholesterol; TG, triglycerides; CK, creatine kinase; BUN, blood urea nitrogen; $\mathrm{Cr}$, creatinine; BS, blood sugar; HbA1c, glycosylated hemoglobin; PT, prothrombin time; APTT, activated partial thomboplastin time; WBC, white blood cells; RBC, red blood cells; Hgb, hemoglobin; Hct, hematocrit; PLT, platelet; CEA, carcinoembryonic antigen; $\mathrm{CA}$, cancer antigen.

\section{Discussion}

Mucocele of the appendix is a cystoid extension of the appendix resulting from mucus accumulation in the appendix cavity that was initially described as hydrops processus vermiformis by Rokitansky in 1842 (1). It is a rare pathology of the appendix, accounting for $0.07-0.3 \%$ of all appendectomy cases $(2,3)$.
A

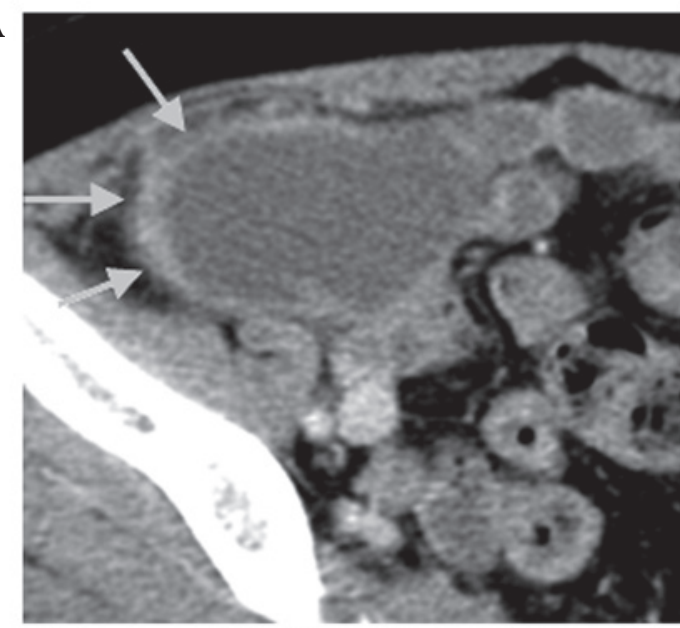

B

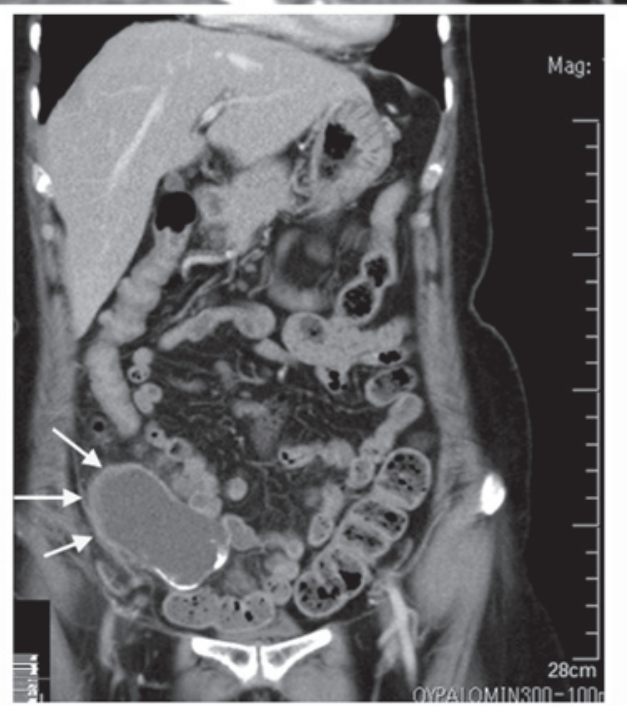

Figure 2. Abdominal computed tomography (CT) scans obtained in August 2012. Axial view (A) and coronal view (B) show no change in the size of the cystic mass at the site of the appendix. Thickening of the mass wall on the appendicular ostium was visible, with contrast enhancement at the corresponding site (arrow). No projection was visible in the mass cavity.

Mucocele of the appendix commonly affects middle-aged to older females and is often accompanied by discomfort or pain and a palpable mass in the right lower quadrant. However, symptoms are non-specific in a number of cases and 20-30\% of cases are diagnosed without symptoms (5).

Kalmon and Winningingham (6) defined three factors that lead to the development of mucocele of the appendix: progressive narrowing of the valvular opening of the appendix, aseptic content and sustained mucus production. Causes of obstruction include inflammation, bending, torsion and ileocecal tumor. The most commonly used pathological classification system was developed by Higa et al (7), who defined the following three types and reported their respective incidence: i) focal or diffuse mucosal hyperplasia (25\%); ii) mucinous cystadenoma (63\%); and iii) mucinous cystadenocarcinoma (12\%).

With conventional imaging techniques, findings suggestive of adenoma have been observed in a number of cases of mucinous cystadenocarcinoma of the appendix, making it difficult to distinguish precisely between the two types of lesions. In addition, since a ruptured mass may lead to pseudomyxoma peritonei (8), surgery is often performed immediately after 

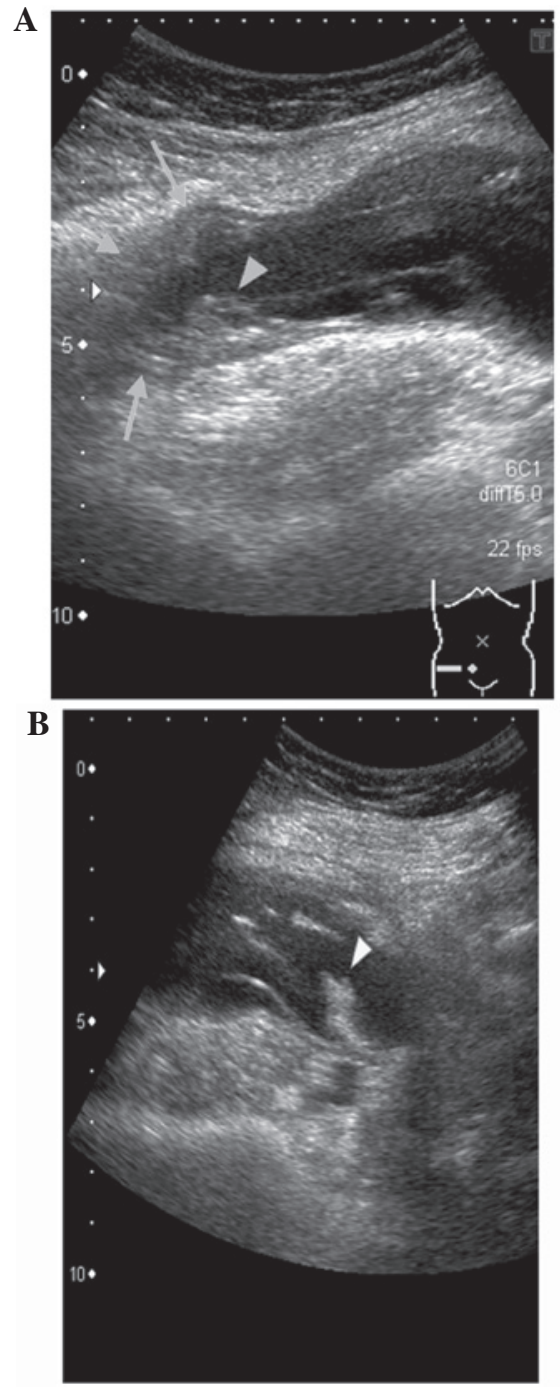

Figure 3. Abdominal ultrasonograms obtained in August 2012. An anechoic mass with a partly layered echo pattern was visible from the appendicular ostium (A) and from the appendicular tip (B). The mass wall on the appendicular ostium was thickened (A, arrow), with a $13-\mathrm{mm}$ projection protruding toward the cavity from part of the wall. Another $9-\mathrm{mm}$ projection was visible on the appendicular tip (B, arrowhead).

diagnosis. However, recent advances in imaging modalities have led to improved accuracy of preoperative diagnosis of the condition $(9,10)$, and US and CT have proved effective for diagnosing mucocele of the appendix $(4,11)$.

On CT, the lesion is visualized as a round or oval, encapsulated, large cystic mass $(12,13)$. Calcification of the cyst wall is highly specific to this lesion and has been shown to be a useful feature for differentiating the cyst from an abscess $(4,14,15)$. It is considered difficult to distinguish between the two lesions based only on wall thickening and the presence of a focal nodular lesion in the tumor cavity in the cyst cavity is considered a potentially important predictor of malignancy (4). Balthazar et al (16) suggested that mucinous cystadenocarcinoma of the appendix is visualized on CT as an irregular, unilocular or multilocular, low-density area with infiltration into adjacent organs, which is specific compared with other types of mucocele of the appendix. In the present case, however, the lesion was visualized as a round, low-density area. This is may be due to the fact that the carcinoma arising from the
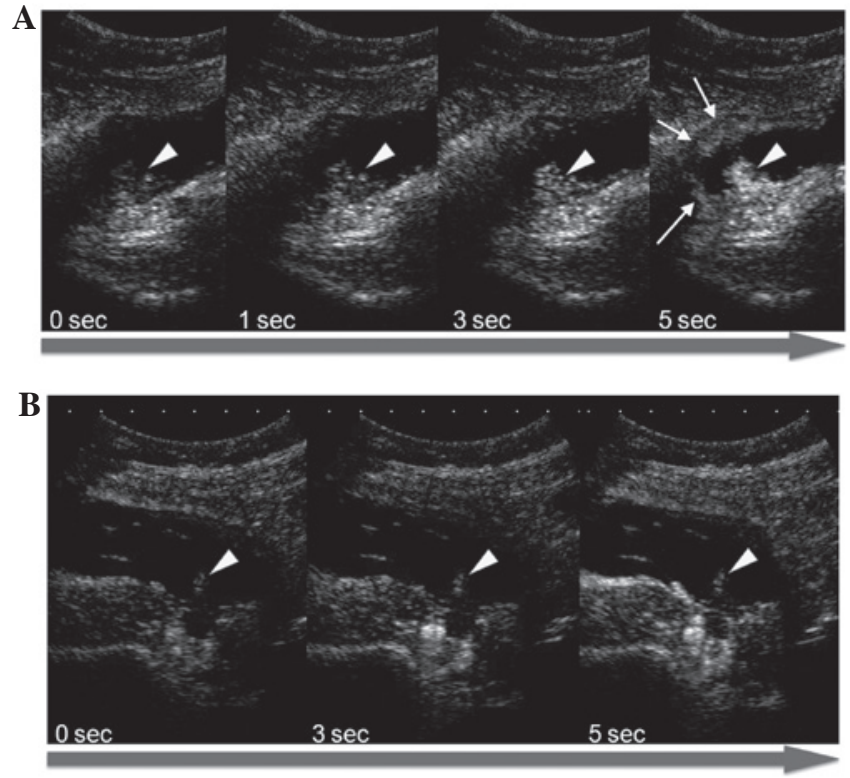

Figure 4. Abdominal contrast-enhanced ultrasonograms obtained in August 2012. A mass was visible from (A) the appendicular ostium and (B) from the appendicular tip. The mass wall (A, arrow) and the projection (A, arrowhead) on the appendicular ostium were enhanced within $5 \mathrm{sec}$ of contrast agent arrival, whereas no enhancement was visible in the projection on the appendicular tip (B, arrow head).

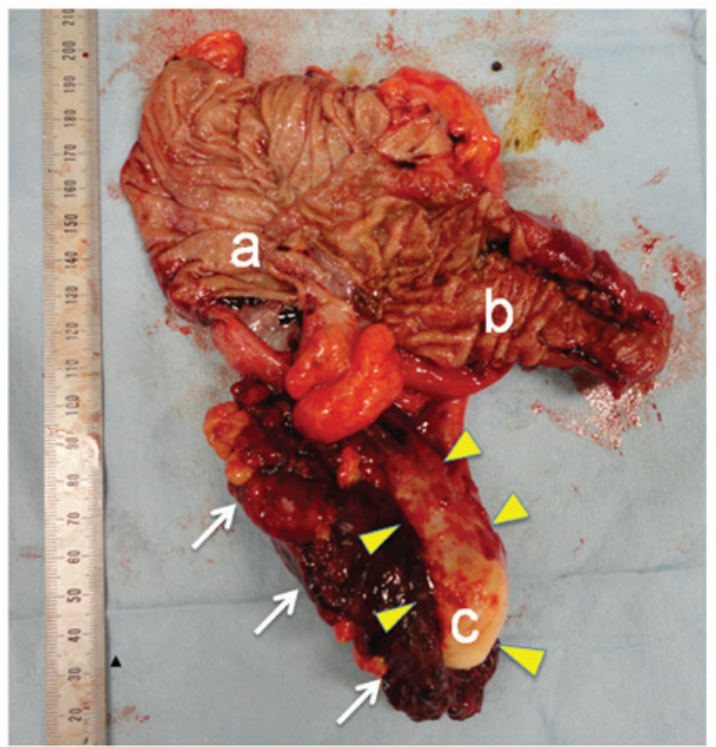

Figure 5. Macroscopic appearance of the excised mass. The appendix was swollen due to a $60-\mathrm{mm}$ cyst with a glossy white surface (arrowhead). The mass was circumscribed by connective tissue (arrow). (a) Ileocecal region; (b) distal ileum; (c) appendix.

appendicular ostium infiltrated only up to the mesoappendix, as confirmed pathologically.

Characteristic US findings include an anechoic or hypoechoic area in the mass (4), as well as fine punctuate, spiral or layered echo patterns $(4,11,17-19)$. Spiral or layered echo patterns observed on US are considered to represent highly viscous mucus, which is referred to by Caspi $e t$ al as an 'onion skin sign', a finding specific to mucocele of the appendix (17). In the present case, layered echo patterns consisting primarily of an anechoic area were also observed in the mass. In addition, 

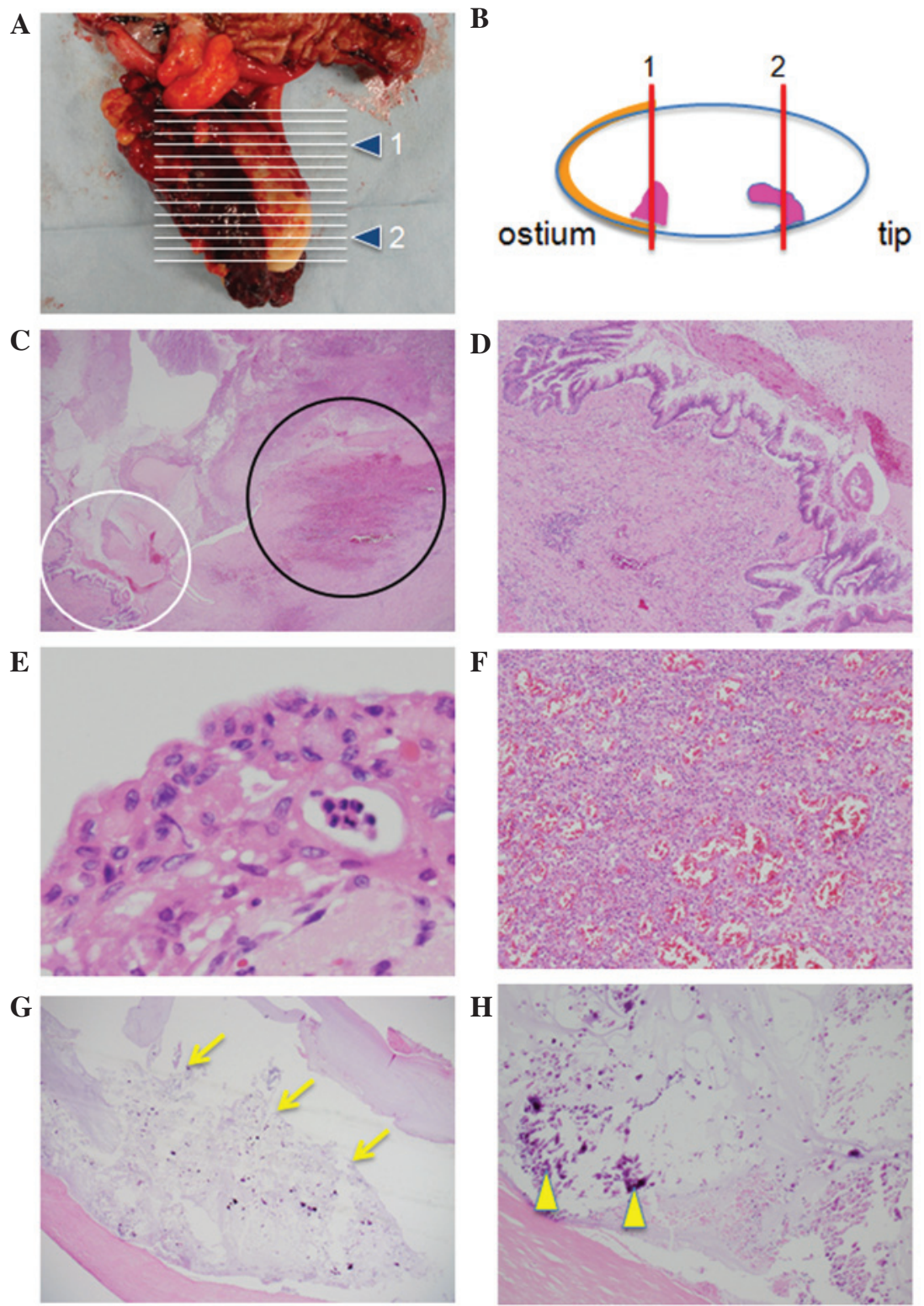

Figure 6. Histopathological findings of the excised mass. (A) Method for slicing the mass and (B) its schematic. Slice 1: (C) enlarged nuclei and pseudostratified cells were visible on the appendicular ostium, which led to the diagnosis of carcinoma: (white circle); hematoxylin and eosin (H\&E); magnification x1; (D) H\&E; magnification, x4; (E) H\&E; magnification, x400. In the tumor cavity [black circle in (C)]: (F) granulation tissue with proliferating capillaries was visible (H\&E; magnification, $\mathrm{x} 10)$. Slice 2: The projection on the appendicular tip showing $(\mathrm{G})$ mucus (arrow, H\&E; magnification, $\mathrm{x} 1)$ and $(\mathrm{H})$ calcification in part of the wall (arrowhead, H\&E; magnification, x100).

a thickened mass wall on the appendicular ostium and projections in the mass cavity were also observed. A previous study suggested that a definitive diagnosis of carcinoma was not made on the basis of wall thickening alone since the presence of projections in the mass cavity is an important finding that strongly suggests carcinoma (4). A detailed examination of the surgical specimen revealed that the projection on the appendicular ostium was a granulation tissue that protruded into the lumen and came into contact with the carcinoma. Although it is unclear how the granulation tissue was formed, we assume that it was a secondary reaction to proliferating carcinoma cells. Thus, a mucocele of the appendix with projection(s) in the mass cavity is likely to be solidified mucus, a mass of carcinoma cells or granulation tissue formed in response to carcinoma proliferation. The projections in the mass cavity were subjected to CEUS for assessment of blood flow. CEUS is being increasingly used as a first-line tool for detecting and characterizing hepatic liver lesions (20-25). Since its introduction to Japan in January 2007, the ultrasound contrast agent Sonazoid has been used in detailed studies on liver tumors (26-34), chronic liver disease (35-40) and other organs $(41,42)$.

While the usefulness of color Doppler US has been suggested for determining whether a projection is mucus or a solid mass (43), CEUS provides a higher level of spatial resolution and more detailed information on blood flow and is thus used to rule out solidified mucus. We consider that CEUS is an important tool for determining the treatment strategy. With no previous study closely examining the mucocele of the appendix by CEUS, future studies should consider this modality as an important preoperative diagnostic tool for this condition. 
We experienced a case of mucinous cystadenocarcinoma of the appendix in which thickening of the mass wall was observed 1 year and 7 months after the first presentation. In the present case, projections in the mass cavity, which were not visualized on abdominal CT, were successfully visualized by B-mode US. Furthermore, the use of CEUS made it possible to determine precisely whether the projections were solidified mucus or a solid tumor. These findings suggest the utility of B-mode US combined with $\mathrm{CT}$ for diagnostic imaging of mucocele, with CEUS being particularly useful for the assessment of blood flow in projections.

\section{References}

1. Rokitansky KF: Beritrage zur Erkrankungen der Wurmfortsazentzundung. Wien Med Presse 26: 428-435, 1866 (In German).

2. González Moreno S, Shmookler BM and Sugarbaker PH: Appendiceal mucocele. Contraindication to laparoscopic appendectomy. Surg Endosc 12: 1177-1179, 1998.

3. Blair NP, Bugis SP, Turner LJ and MacLeod MM: Review of the pathologic diagnoses of 2,216 appendectomy specimens. Am J Surg 165: 618-620, 1993.

4. Kim SH, Kim HK, Lee WJ, et al: Mucocele of the appendix; ultrasonographic and CT findings. Abdom Imaging 23: 292-296, 1998

5. Yajima H, Kokudo N, Takahashi T, et al: A case of appendiceal mucocele diagnosed preoperatively by ultrasonography. J Med Ultrasonics 29: 171-175, 2002 (In Japanese).

6. Kalmon EH and Winningingham EV: Mucocele of the appendix. Am J Roentgenol Radium Ther Nucl Med 72: 432-435, 1954

7. Higa E, Rosai J, Pizzimbono CA and Wise L: Mucosal hyperplasia, mucinous cystadenoma, and mucinous cystadenocarcinoma of the appendix. A re-evaluation of appendiceal "mucocele". Cancer 32: 1525-1541, 1973.

8. Morson BC (ed): Gastrointestinal Pathology. 2nd edition. Blackwell Scientific Publications, London, pp449-482, 1979.

9. Kahn M and Friedman IH: Mucocele of the appendix: diagnosis and surgical management. Dis Colon Rectum 22: 267-269, 1979.

10. Simmons K and Sage MR: Mucocele of the appendix. Australas Radiol 23: 33-35, 1979.

11. Degani S, Shapiro I, LeibovitZ Z and Ohel G: Sonographic appearance of appendiceal mucocele. Ultrasound Obstet Gynecol 19: 99-101, 2002.

12. Horgan JG, Chow PP, Richter JO, et al: CT and sonography in the recognition of mucocele of the appendix. AJR Am J Roentgenol 143: 959-962, 1984

13. Matsumoto K, Kanazawa S and Segawa K: A case of mucinous cystadenoma of appendix with a characteristic image on abdominal ultrasonography. Gastroenterol Endosc 30: 999-1004, 1988 (In Japanese).

14. Pickhardt PJ, Levy AD, Rohrmann CA Jr and Kende AI: Primary neoplasms of the appendix: radiologic spectrum of disease with pathologic correlation. Radiographics 23: 645-662, 2003.

15. Madwed D, Mindelzun R and Jeffrey RB Jr: Mucocele of the appendix: imaging findings. AJR Am J Roentgenol 159: 69-72, 1992.

16. Balthazar EJ, Megibow AJ, Gordon RB, et al: Computed tomography of the abnormal appendix. J Comput Assist Tomogr 12: 595-601, 1988.

17. Caspi B, Cassif E, Auslender R, et al: The onion skin sign: a specific sonographic marker of appendiceal mucocele. J Ultrasound Med 23: 117-121, 2004.

18. Athey PA, Hacken JB and Estrada R: Sonographic appearance of mucocele of the appendix. J Clin Ultrasound 12: 333-337, 1984.

19. Fallon MJ, Low VH and Yu LL: Mucunous cystadenoma of the appendix with unusual sonographic appearance. Australas Radiol 38: 339-341, 1994.

20. Bartolotta TV, Midiri M, Quaia E, et al: Benign focal liver lesions: spectrum of findings on SonoVue-enhanced pulse-inversion ultrasonography. Eur Radiol 15: 1643-1649, 2005.

21. Dietrich CF: Characterisation of focal liver lesions with contrast enhanced ultrasonography. Eur J Radiol 51 (Suppl): S9-S17, 2004.

22. Iijima H, Moriyasu F, Tsuchiya K, et al: Decrease in accumulation of ultrasound contrast microbubbles in non-alcoholic steatohepatitis. Hepatol Res 37: 722-730, 2007.
23. Fujita Y, Watanabe M, Sasao K, et al: Investigation of liver parenchymal flow using contrast-enhanced ultrasound in patients with alcoholic liver disease. Alcohol Clin Exp Res 28 (Suppl Proceedings): 169S-173S, 2004.

24. Ogawa S, Kumada T, Toyoda H, et al: Evaluation of pathological features of hepatocellular carcinoma by contrast-enhanced ultrasonography: comparison with pathology on resected specimen. Eur J Radiol 59: 74-81, 2006.

25. Basilico R, Blomley MJ, Harvey CJ, et al: Which continuous US scanning mode is optimal for the detection of vascularity in liver lesions when enhanced with a second generation contrast agent? Eur J Radiol 41: 184-191, 2002.

26. Takahashi M, Maruyama H, Ishibashi H, Yoshikawa $M$ and Yokosuka O: Contrast-enhanced ultrasound with perflubutane microbubble agent: evaluation of differentiation of hepatocellular carcinoma. AJR Am J Roentgenol 196: W123-W131, 2011.

27. Hiraoka A, Hirooka M, Koizumi Y, et al: Modified technique for determining therapeutic response to radiofrequency ablation therapy for hepatocellular carcinoma using US-volume system. Oncol Rep 23: 493-497, 2010.

28. Luo W, Numata K, Kondo M, et al: Sonazoid-enhanced ultrasonography for evaluation of the enhancement patterns of focal liver tumors in the late phase by intermittent imaging with a high mechanical index. J Ultrasound Med 28: 439-448, 2009.

29. Shiozawa K, Watanabe M, Kikuchi Y, et al: Evaluation of sorafenib for hepatocellular carcinoma by contrast-enhanced ultrasonography: a pilot study. World J Gastroenterol 18: 5753-5758, 2012 .

30. Kudo M: New sonographic techniques for the diagnosis and treatment ofhepatocellular carcinoma. Hepatol Res 37 (Suppl 2): S193-S199, 2007.

31. Wakui N, Takayama R, Kamiyama N, et al: Diagnosis of hepatic hemangioma by parametric imaging using sonazoid-enhanced US. Hepatogastroenterology 58: 1431-1435, 2011.

32. Shiozawa K, Watanabe M, Takayama R, et al: Evaluation of local recurrence after treatment for hepatocellular carcinoma by contrast-enhanced ultrasonography using Sonazoid: comparison with dynamic computed tomography. J Clin Ultrasound 38: $182-189,2010$.

33. Wakui N, Sumino Y and Kamiyama N: A case of high-flow hepatic hemangioma: analysis by parametoric imaging using sonazoid-enhanced ultrasonography. J Med Ultrasonics 37: 87-90, 2010.

34. Wakui N, Takayama R, Matsukiyo Y, et al: A case of poorly differentiated hepatocellular carcinoma with intriguing ultrasonography findings. Oncol Lett 4: 393-397, 2012.

35. Wakui N, Takayama R, Kanekawa T, et al: Usefulness of arrival time parametric imaging in evaluating the degree of liver disease progression in chronic hepatitis C infection. J Ultrasound Med 31: 373-382, 2012.

36. Wakui N, Takayama R, Mimura T, Kamiyama N, Maruyama K and Sumino Y: Drinking status of heavy drinkers detected by arrival time parametric imaging using sonazoid-enhanced ultrasonography: study of two cases. Case Rep Gastroenterol 26: 100-109, 2011.

37. Wakui N, Fujita M, Oba N, et al: Endoscopic nasobiliary drainage improves jaundice attack symptoms in benign recurrent intrahepatic cholestasis: A case report. Exp Ther Med 5: 389-394, 2013.

38. Ishibashi $\mathrm{H}$, Maruyama $\mathrm{H}$, Takahashi $\mathrm{M}$, et al: Assessment of hepatic fibrosis by analysis of the dynamic behaviour of microbubbles during contrast ultrasonography. Liver Int 30: 1355-1363, 2010.

39. Yoshikawa S, Iijima H, Saito M, et al: Crucial role of impaired Kupffer cell phagocytosis on the decreased Sonazoid-enhanced echogenicity in a liver of a nonalchoholic steatohepatitis rat model. Hepatol Res 40: 823-831, 2010.

40. Wakui N, Takayama R, Matsukiyo Y, et al: Visualization of segmental arterialization with arrival time parametric imaging using Sonazoid-enhanced ultrasonography in portal vein thrombosis: A case report. Exp Ther Med 5: 673-677, 2013

41. Onji K, Yoshida S, Tanaka S, et al: Microvascular structure and perfusion imaging of colon cancer by means of contrast-enhanced ultrasonography. Abdom Imaging 37: 297-303, 2012.

42. Imazu H, Uchiyama $\mathrm{Y}$, Matsunaga $\mathrm{K}$, et al: Contrast-enhanced harmonic EUS with novel ultrasonographic contrast (Sonazoid) in the preoperative T-staging for pancreaticobiliary malignancies. Scand J Gastroenterol 45: 732-738, 2010.

43. Kameda T, Kawai F, Kase K, et al: Three cases of appendiceal mucocele: specific ultrasonographic findings. Jpn J Med Ultrasonics 33: 229-237, 2006 (In Japanese). 